\title{
COMBÈs Isabelle y Vera TYULENEVA (eds), Paititi. Ensayos y documentos
}

\author{
Pablo F. Sendón
}

\section{CpenEdition}

\section{Journals}

\section{Edición electrónica}

URL: https://journals.openedition.org/jsa/12436

DOI: $10.4000 /$ jsa. 12436

ISSN: $1957-7842$

\section{Editor}

Société des américanistes

\section{Edición impresa}

Fecha de publicación: 31 diciembre 2012

Paginación: 263-269

ISSN: 0037-9174

\section{Referencia electrónica}

Pablo F. Sendón, «combès Isabelle y Vera tyuleneva (eds), Paititi. Ensayos y documentos», Journal de la Société des américanistes [En línea], 98-2 | 2012, Publicado el 05 junio 2013, consultado el 03 septiembre 2022. URL: http://journals.openedition.org/jsa/12436 ; DOl: https://doi.org/10.4000/jsa. 12436

Este documento fue generado automáticamente el 3 septiembre 2022.

All rights reserved 


\title{
COMBÈs Isabelle y Vera TYULENEVA (eds), Paititi. Ensayos y documentos
}

\author{
Pablo F. Sendón
}

\section{REFERENCIA}

COMBÈs Isabelle y Vera TYULENEVA (eds), Paititi. Ensayos y documentos, Instituto

Latinoamericano de Misionología/Editorial Itinerarios, Cochabamba, 2011, 458 p., bibl., ill., cartes

1 Un río, una laguna, una montaña, una tierra, un lugar, una región, un nombre propio de un jefe étnico, una gobernación, una utopía... todas estas atribuciones, y otras más, han sido, y siguen siendo, prerrogativas del vocablo « Paititi », que parecieran hundirlo en un halo de misterio del que el presente volumen procura rescatar, restituyendo sus dimensiones históricas y atendiendo en particular a la «cara indígena de La Noticia » (p. 2) a lo largo de los siglos xvi y xviII.

2 Como lo anuncia su título, el libro está organizado en dos grandes bloques. El primero está constituido por nueve ensayos dedicados a explorar y analizar las expediciones incas a la Amazonía peruano-boliviana (el Antisuyu) y las narraciones contemporáneas sobre el tema, las migraciones guaraníes hacia el Occidente, la huella jesuita en la búsqueda colonial del Paititi y la historia efímera, y por añadidura tardía, del Paititi de Larecaja. El segundo de los bloques está conformado por un corpus documental de envergadura organizado en once anexos que reúne fuentes éditas (cinco) e inéditas (seis) sobre el Paititi perteneciente al período contemplado. En palabras de las editoras, el volumen no pretende alcanzar una mirada totalizadora, completa ni definitiva sino que propone un « estado de la cuestión de la investigación sobre el tema » (p. 3). Veamos.

3 Inaugura el volumen el ensayo de Vera Tyuleneva concentrado en la compilación, ordenamiento y análisis de fuentes (éditas) que brindan información acerca de las entradas de los ejércitos incas a los territorios de la Amazonía - en particular a aquellos ubicados al este del Cuzco - en busca de coca, oro, bienes suntuarios de la selva así como 
del sometimiento de poblaciones más o menos hostiles. Las fuentes relatan incursiones « en tiempos de » los reinados de Inca Roca, Pachacutec/Tupac Yupanqui y Huayna Capac - así como también un "singular relato" (p.17) que atribuye a Inca Yupanqui, Rey ignorado en otras crónicas, la entrada a las tierras los musus. Además de proporcionar rica información acerca de etnónimos y topónimos (entre los cuales Patite o Paytite aparece asociado al nombre de un río), la autora identifica tres etapas cronológicas de expediciones militares incas hacia la selva - que sólo de manera cuestionable se basarían, según su entender, en las cronologías atribuidas a los reinados incas - en virtud de las cuales la primera de ellas habría alcanzado las zonas limítrofes a las cabeceras del río Madre de Dios, la segunda las provincias de Carabaya y Apolobamba y la tercera la región de Cochabamba y Santa Cruz coincidentes, todas ellas, con porciones de los territorios del Antisuyu y el Collasuyu. La identificación de esta serie de expediciones permitiría, aunque no sin inconvenientes, sentar los fundamentos históricos, consideraciones arqueológicas mediante, del mito del Paititi en clave de " último refugio de los incas ». Precisamente a ello están dedicados los siguientes tres ensayos del libro.

4 A propósito del mito del héroe fundador Inkarrí y su destino final en la selva - hasta hace relativamente poco tiempo bastante extendido entre las poblaciones campesinoindígenas cuzqueñas de las provincias de Calca, La Convención y Paucartambo -, Gregory Deyermenjian se concentra en describir un camino de piedra que se desliza a lo largo de la cordillera de Paucartambo en dirección al piedemonte y que se encuentra, a su vez, atravesado transversalmente por caminos secundarios que la tradición local vincula con « caminos al Paititi» (p. 25). Si bien existen evidencias arqueológicas que corroboran la presencia e incluso ocupación incaica en los territorios septentrionales de la cordillera, es poco probable la existencia de una ciudad refugio de los incas en la región. Para el autor, en cambio, la «ciudad dorada " no habría sido otra cosa que una imagen del mismo Cuzco, imaginado y descrito por poblaciones guaraní-chiriguanas y que « rebotó » de nuevo en la selva allí donde los serranos ubican al Paititi.

5 Jorge Flores Ochoa, por su parte, ofrece una serie de referencias - más bien sueltas acerca de «la Noticia» que retoma algunas (dos) tradiciones mitológicas cuzqueñas relativas a ciudades incas perdidas y una mención, de por sí interesante pero sin mayores especificaciones, de una expedición de Juan María Pacheco en 1836 hacia el piedemonte andino motivada por la presunta existencia del "Camante» más allá del valle de Marcapata, otra región donde eventualmente existiría una ciudad inca perdida.

6 La contribución de Donato Amado, finalmente, vuelve a retomar el problema de la entrada de los incas a la selva, a partir de crónicas y registros arqueológicos, prestando especial atención a los caminos reales (Qhapaq Ñan) y al sistema vial del Antisuyu. Estos caminos fueron abandonados tras la invasión ibérica y vueltos a utilizar más tarde por los mismos españoles en sus propias incursiones a la selva entre las que destaca, quizás, la expedición de Juan Álvarez Maldonado hacia fines del siglo Xvi a los valles de los ríos Tono, Cuchoa y hacia el mismísimo Paititi, cuya búsqueda a fines del siglo xIX todavía formaba parte de las quimeras de los primeros caucheros del Madre de Dios y, desde mediados del siglo pasado, de expediciones científicas de diversa índole y envergadura.

7 El trabajo de Isabelle Combès, que en cierto modo recoge el guante arrojado por Deyermenjian en su contribución, está abocado a desentrañar a partir del estudio de fuentes del siglo XVI y comienzos del XVII los procesos migratorios desde el otro lado del espejo, es decir, las incursiones guaraníes y chiriguanaes desde distintas regiones de las así denominadas «tierras bajas» hacia sus pares de las «tierras altas». Antecede a la 
discusión propiamente dicha una serie de consideraciones dedicadas a las expediciones que desde el río de La Plata (Buenos Aires y Asunción), Santa Cruz de la Sierra y Charcas realizaron los españoles hacia Mojos o Paititi, con el propósito de advertir al lector que «la Noticia» no consistió en una utopía exclusivamente española, sino que existió también una " cara indígena » que supo alimentar los sueños de los iberos y diseñar las estrategias de sus respectivas entradas - muchas de las cuales siguieron las rutas trazadas por las mismas poblaciones indígenas. Las migraciones chiriguanaes no deben tomarse como un bloque monolítico, ya que están relacionadas con grupos guaraní-hablantes de origen diverso y se sucedieron de manera escalonada a lo largo del tiempo. En lo que respecta a sus orígenes históricos, ellas cubren un arco temporal cuya datación, en el período precolombino, queda - más allá de que se haya sugerido el siglo IV después de Cristo como punto de origen - como un problema abierto, y continúan a lo largo de la Colonia. Los motivos de las migraciones son, por lo menos, tres. Durante la Colonia, ellas expresan las ansias de las poblaciones indígenas de huir de la presencia española y la esclavitud. Durante el período precolombino, ellas estarían relacionadas con la búsqueda de metales preciosos en el Occidente así como también con el no menos problemático fenómeno de la búsqueda de una "tierra sin mal»-acerca del cual la autora se pronuncia cautelosa, detallada y en cierto modo escépticamente - ampliamente generalizado, y extrapolado a-históricamente, en y por gran parte de la etnología amazónica. Pero el análisis no culmina allí. Combès lleva al lector a adentrarse en las incursiones de los guaraníes/chiriguanaes quienes, desde el Paraguay, perseguían a los pueblos « señores del metal » entre los que destacan los candires y caracaraes, dueños de las minas de Samaipata y Saypuru. En rigor, todo parecería indicar que « candires » era un término aplicado a los propios « incas ", dueños efectivos de las minas, asentados al oeste del río Guapay - frontera oriental del imperio - y « caracaraes » o " qaraqaras » eran términos utilizados para los andinos de Charcas que fueron empleados en Saypurú. Según algunas relaciones, un contingente de chiriguanaes se desprendió del grupo mayor en dirección noroeste, en busca del "Rey Blanco ", "Pai Sumé » o, en clave jesuítica, «Santo Tomás » y el « reino del Paititi llamado Mojos » fundado por Manco Inca. En sus propias expediciones para encontrar a los candires y el Paititi, los españoles no hicieron sino seguir las rutas prehispánicas y sus mejores informantes fueron los chiriguanaes. Ahora bien, ¿cómo relacionar estas incursiones indígenas y españolas desde las tierras bajas con el Paititi de tradición cuzqueña? Más allá de los problemas involucrados en la supuesta ubicuidad del Paititi, Combès propone la siguiente hipótesis: "Paititi es primero un nombre, una creencia y una búsqueda guaraní. Todo parece evidenciar un encuentro o un choque de creencias entre indígenas andinos y de las tierras bajas primero, a las cuales se sumaron luego ingredientes españoles » (p. 98).

8 Entre los ingredientes en cuestión destaca la huella jesuita en la búsqueda colonial del Paititi. Al rastreo de esta huella se abocan los dos capítulos subsiguientes del libro. En el primero de ellos, Mario Polia presenta, traduce y comenta un documento del Archivo Romano de la Compañía de Jesús de 1584 que relata el encuentro del entonces rector del Colegio de Cuzco con el rey del Paititi, su hijo el príncipe heredero y un grupo de nobles quienes viajaron a la ciudad imperial para entrevistarse con él tras haber experimentado un milagro y una conversión. Adicionalmente el documento hace referencia a un encuentro en Roma entre el rector del Colegio del Cuzco y el mismo Papa Gregorio XIII a quien el primero le entregó en obsequio una piedra bezoar de tamaño inusitado, objeto de culto entre los indios adoradores de la luna antes de su conversión - quien dio licencia a la Compañía de enviar misioneros al Paititi. De la lectura del documento el autor 
concluye que la hipótesis de que después de la ocupación española y la derrota de las últimas huestes de Vilcabamba un grupo de la nobleza incaica buscó un lugar más alejado para la reconquista del Tawantinsuyu no puede ser descartada a priori. Asimismo, propone también, a manera de hipótesis, la eventual existencia, en la ceja de selva, de altas culturas amazónicas anteriores a los incas y no sujetas a la influencia cultural incaica.

9 Por su parte, Laura Laurencich Minelli analiza dos documentos « secretos » jesuíticos, el Exsul Immeritus Blas Valera Populo Suo (1618), del propio Blas Valera, y la Historia et Rudimento Linguae Piruanorum (c. 1600-1737), firmado por varias manos, consistentes, respectivamente, en un programa en defensa de los indios y su ulterior desarrollo e implementación. Debido al carácter « secreto » (e incluso « conspirativo ») que mantuvo a ambos documentos fuera del alcance del público (religioso, especialista o lego) hasta tiempos recientes, así como también a la no menos problemática acreditación, por parte de la autora, de la autoría de la Nueva Corónica y Buen Gobierno de Felipe Guaman Poma de Ayala al mismo Valera, la lectura de los documentos analizados no sólo debe contemplar la de la Nueva Corónica sino que, al hacerlo, ellos arrojarían nuevas luces sobre ella. Los documentos en cuestión contienen serias denuncias a los hechos inauditos que siguieron al proceso de invasión y conquista del Tawantinsuyu y proponen un programa de reforma consistente en la realización de un nuevo reino inca y cristiano con el fin de devolver la libertad a los indios. Ahora bien, ¿qué tiene que ver todo esto con el Paititi? En efecto, y como no deja de observar la autora, «el Paytiti está completamente silenciado tanto en la Nueva Corónica como en Historia et Rudimento y, si bien Exsul Immeritus lo menciona, lo hace de manera [...] críptica» (p.150). La respuesta a esta cuestión está relacionada con el análisis que Laurencich realiza de la documentación ponderada - que excede el registro escrito - y la documentación entrecruzada que pareciera confirmarla. En virtud de todo ello, el Paititi consistiría en una utopía, es decir, sería el programa de reforma impulsado por los jesuitas valerianos para instaurar un reino inca cristiano en la Tierra. Incluso más, el Paititi consistiría en los mismos documentos que promueven dicho « proyecto novedoso » $\mathrm{y}$ « mestizo » plausible de ser interpretado en términos de « mitos de fundación del cristianismo » (p. 156).

10 El trabajo de Albert Meyers e Isabelle Combès vuelve a retomar varios de los problemas desplegados hasta aquí a propósito de una Relación Cierta firmada por Diego Felipe de Alcaya, cura de Mataca, a partir de lo escrito por su padre, el capitán Martín Sánchez de Alcayaga. La Relación resulta un documento de alta estima para la reconstrucción temprana del actual Oriente boliviano. El texto, que gira alrededor de un único tema - el de los incas orientales y los tesoros que se encuentran bajo su posesión y al alcance de aquellos exploradores que busquen alcanzarlos - cuenta dos historias paralelas: la de los hermanos incas Guacane y Condori asentados en Samaipata y las minas de Saypurú en la cordillera chiriguana y la de Manco Inca en Mojos o Paititi. Ambas historias tienen puntos en común: transcurren en la misma época antes de la llegada de los españoles, implican avances de poblaciones andinas hacia el este del Cuzco, involucran la conformación de « reinos satélites » cuyas relaciones con la ciudad imperial distan de no ser problemáticas y constituyen los focos de las migraciones chiriguanaes, primero, $\mathrm{y}$ españolas, después, en busca de la « tierra rica ».

11 En consonancia con este trabajo, cierra el bloque ensayístico del volumen un artículo de las editoras en el que se presentan y discuten varios documentos de la segunda mitad del siglo xviII en los que diferentes pueblos de la zona de Larecaja, al sureste de Apolobamba, 
son denominados «provincias » o « misiones » del Gran Paititi. El rastreo del origen de esta identificación, de por sí tardía, entre Larecaja y la « Tierra Rica » es el pretexto que lleva a las autoras a incursionar en el problema del antiguo poblamiento étnico de una vasta región corredor entre tierras «altas " y «bajas»-el piedemonte andino desde Apolobamba y el Chapare - en la que, en el siglo xIx, el nombre del Gran Paititi desaparece del mapa étnico regional.

$\mathrm{El}$ anexo documental del libro, sobre el que se fundamentan algunos de los ensayos que lo componen, presenta una serie de documentación inédita - proveniente de los fondos del Archivo General de Indias, el Archivo Nacional de Bolivia y el Museo de Historia de la Universidad Autónoma Gabriel René Moreno de Santa Curz - tal como la «Consulta sobre la entrada a los raches y moxos» de 1644, la «Relación Mirabalina» de 1661, las "Cartas de Antonio López de Quiroga y Benito de Rivera y Quiroga» de 1670, la «Relación Mirabalina II: Entradas de Benito de Rivera y Quiroga» de 1673-1683, los «Cuadernos de Francisco del Rosario » de 1670-1674 y la « Representación de Bartolomé Oviedo y Correoso para el descubrimiento del Gran Paititi » del año 1734.

En términos generales la presente obra exhibe tres virtudes. La primera de ella, y para citar a una de las editoras, consiste en ponderar el problema del Paititi, más allá de su eventual existencia o entidad, en los términos que propone una historia regional: «Accidentes históricos, estas ciudades propiciaron sin embargo la conquista y la colonización de extensas regiones por parte de los españoles: la Noticia forjó la historia $\mathrm{y}$, como tal, es parte de ella " (p.54). En segundo lugar, y desde una perspectiva etnológica también general, el volumen se presenta como una prueba contundente de que la historia regional de las poblaciones indígenas involucradas en ella - a propósito de la búsqueda de los « Paititis » - no puede ser concebida en términos de compartimentos estancos: "La "frontera" entre Andes y tierras bajas no siempre fue una barrera impermeable - tal vez lo muestra de algún modo el nombre mismo que damos hoy a las sierras occidentales: Andes (Antis), es decir lo que fue la fracción amazónica del imperio inca» (p. 98). La tercera, y no la menos importante, es poner al alcance de los investigadores una serie de documentos hasta hoy inéditos y cuyo valor excede el solo tema del Paititi. Resta a los etnohistoriadores, arqueólogos, antropólogos y lingüistas especializados en el estudio de las poblaciones indígenas que habitaron, y aún habitan, gran parte de los territorios de los Andes y de la Amazonía sudamericana evaluar los aspectos técnicos sobre los que han sido elaboradas y sostienen algunas de las hipótesis de los estudios aquí reseñados.

\section{AUTORES}

PABLO F. SENDÓN

CONICET, Argentina 